\title{
Predicting Success for Meteorology Majors Are Incoming Test Scores Indicative?
}

\author{
Adapted from "Recipe for \\ Successful Meteorology Majors: \\ Are Incoming Test Scores \\ Indicative?" by Craig A. Clark \\ (Valparaiso University). Published \\ online in BAMS, April 2020. \\ For the full, citable article, see \\ DOI:10.1175/BAMS-D-19-0229.1.
}

tandardized test scores (such as the ACT and SAT) and high school grade point average (GPA) are predictive of academic performance, retention, and associated degree completion from undergraduate programs, and this relationship has been found for colleges of all selectivity levels, types of classes, and demographic factors. For example, an ACT math score of 27 indicates a $50 \%$ probability of a B or better grade in first-semester calculus.

The efficacy of incoming test scores in predicting success within meteorology (or atmospheric science) undergraduate programs has not been previously evaluated in the literature. Given the clear costs and benefits of obtaining a bachelor's degree, coupled with the quantitative demands of undergraduate degrees in meteorology (atmospheric science) and the high attrition ( $50 \%)$ within these math-intensive programs, I set out to quantify the attrition risk in meteorology at Valparaiso University 
Student Performance in Meteorology

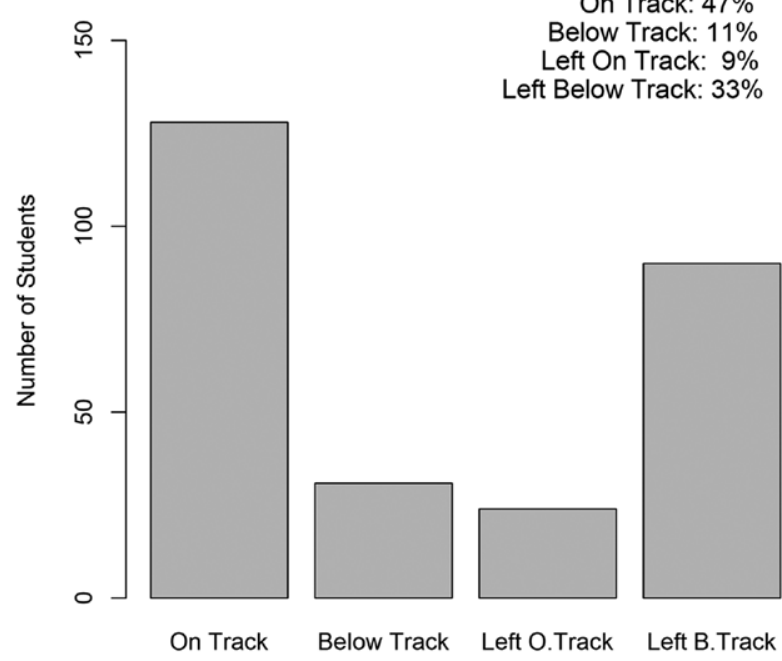

(VU) as it relates to incoming test scores and associated math skill.

\section{Data and methods}

The study assessed seven years of student outcomes of incoming meteorology majors (2008-14 first-year cohorts). Along with an evaluation of reported incoming test scores (ACT only), these students were given classifications related to program success and graduation, as follows: Program graduates who did not need to retake any required mathematics, physics, or meteorology courses to stay above the meteorology/math/physics GPA requirement of 2.3 were on track. Program graduates who had to retake at least one required mathematics, physics, or meteorology course in order to stay above the required GPA, and/or were below this standard for at least one of the semester-end evaluations were below track. Students who were doing fine in the program (B- or better grades in meteorology, math, and physics coursework) but decided to change majors or leave VU left on track. Students who changed majors after struggling (with a $\mathrm{C}+$ or lower) in required meteorology, math, or physics coursework left below track. In terms of graduation, we categorized students who graduated from VU with a major in meteorology, those who graduated from VU with another major, and those who did not graduate from VU.
B.

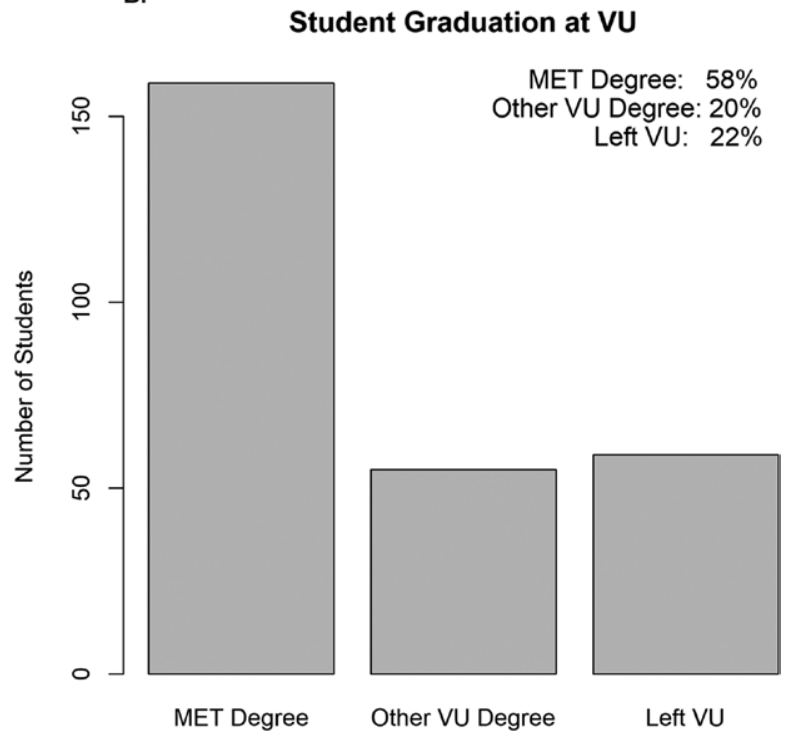

\section{Results}

During this 7-cohort period, 273 students entered the meteorology program at VU, with a similar percentage of male (52\%) and female (48\%) pupils. Most students started as freshman, while 28 transferred from another institution. A little less than half of the students completed the program on track, $11 \%$ completed the program below track, $9 \%$ left on track, and about a third left below track. Roughly 58\% of the students graduated with a meteorology degree, while the rest either graduated with another VU degree or left VU. The combined graduation rate with a VU degree was $78 \%$, with none of the students still working toward their VU undergraduate degree after the completion of the 2017/18 academic year.

Incoming student test scores varied substantially, with a mean ACT Composite of 26.4 (with a range from 18 to 35 ) and ACT Math average of 26.3 (with a range of 16 to 36). Student outcomes were sensitive to incoming scores, with significantly higher average ACT scores for on-track meteorology students 
A.

ACT Composite and Performance in Meteorology

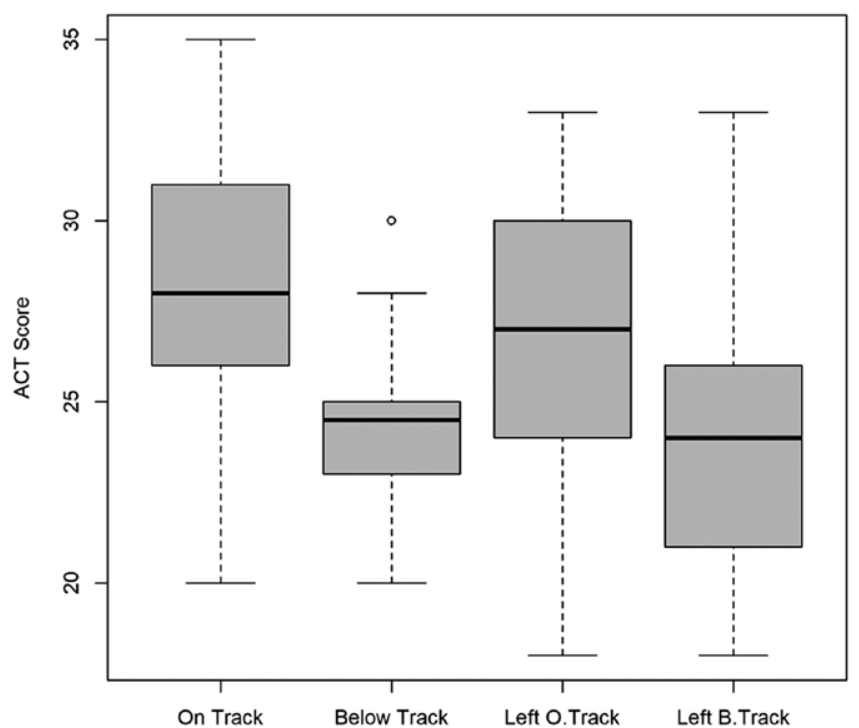

c.

ACT Math and Performance in Meteorology

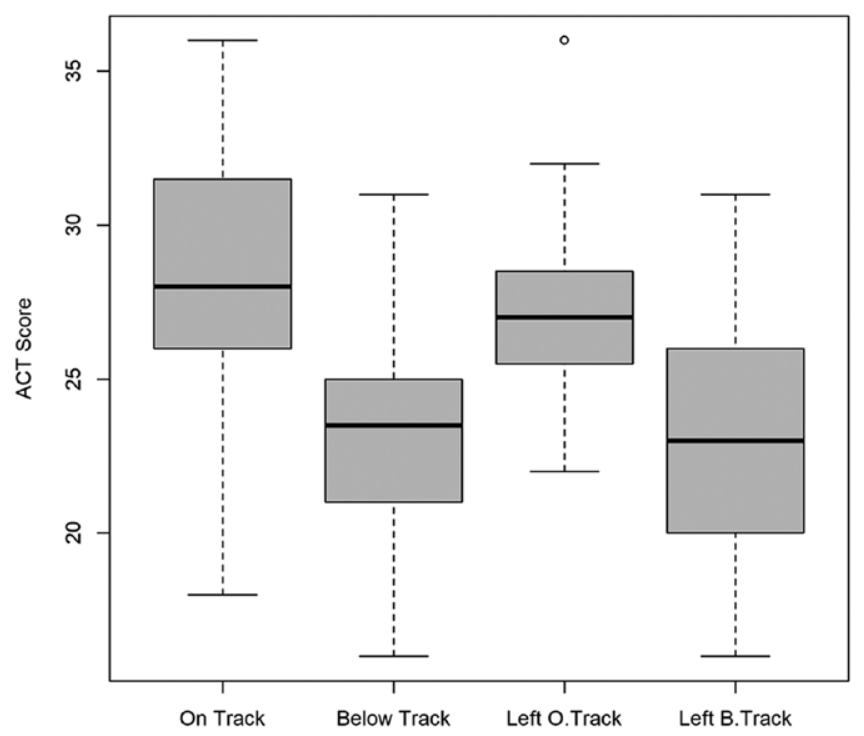

(28.3 Composite; 28.5 Math) and on-track students who left $(26.7 ; 27.5)$ than for students who were either below track $(24.4 ; 23.5)$ or left below track $(24.0 ; 23.2)$. This sensitivity to incoming test scores affected the graduation classification as well, with significantly higher ACT Composite and ACT Math scores for meteorology graduates than other VU degree graduates and those who left VU.

More than 60\% students with ACT Math scores of 23 or less left below track. Prospects
B.

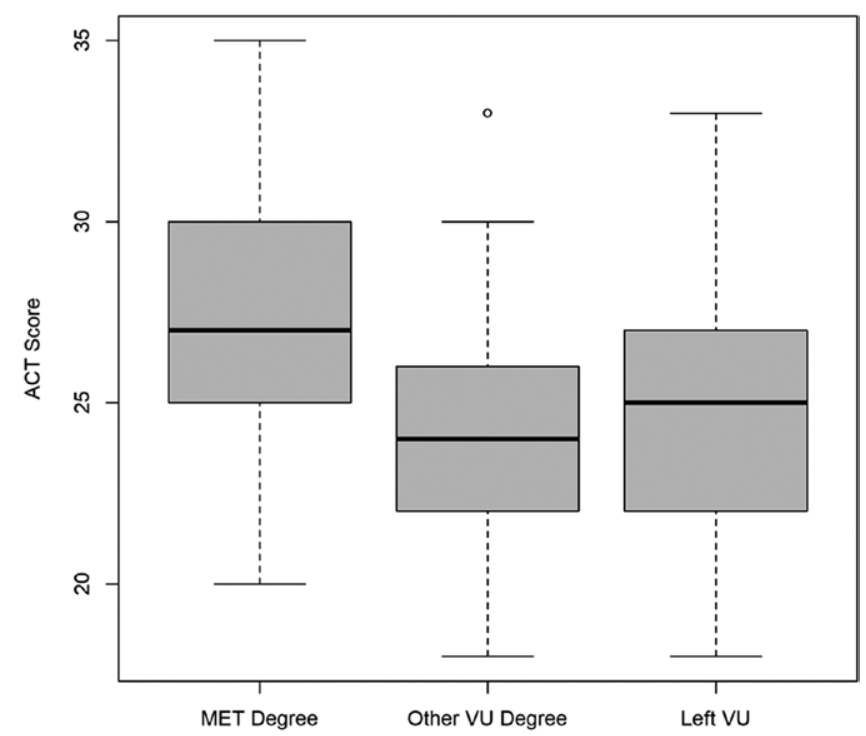

D.

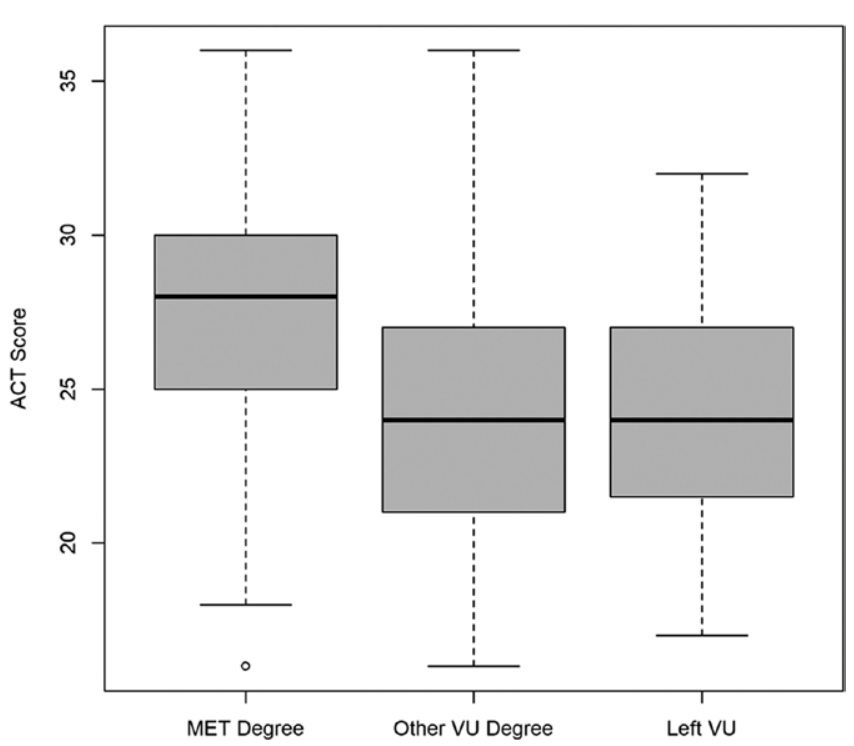

$\triangle$ * Student (top) ACT Composite and (bottom) ACT Math scores among incoming meteorology students, classified by (left) program success and (right) graduation. The differences between the ACT Composite scores among the On Track group (compared with Left Below Track and Below Track groups) are statistically significant; this is also the case for the ACT Math scores. The differences in mean scores between the MET Degree graduates and the other graduation categories are also significant. 


\begin{tabular}{|c|c|c|c|c|}
\hline & \multirow[b]{2}{*}{ Category } & \multicolumn{3}{|c|}{ ACT Math range } \\
\hline & & $16-23$ & $24-26$ & $27-36$ \\
\hline \multirow[t]{4}{*}{ Performance classification } & On Track & 15.8 & 41.7 & 72.2 \\
\hline & Below Track & 19.3 & 16.7 & 3.7 \\
\hline & Left on Track & 1.8 & 14.6 & 10.2 \\
\hline & Left Below Track & 63.2 & 27.1 & 13.9 \\
\hline \multirow[t]{3}{*}{ Graduation classification } & MET Degree & 35.1 & 56.3 & 75.9 \\
\hline & Other VU Degree & 31.6 & 22.9 & 11.1 \\
\hline & Left VU & 33.3 & 20.8 & 13.0 \\
\hline
\end{tabular}

were vastly improved for students with ACT Math scores of 25 and above, with roughly twothirds on track in the major. These impacts carried over to graduation, with a meteorology degree completion rate of $72 \%$ for ACT Math scores of 25 or greater compared to only $35 \%$ of students with ACT Math scores of 23 or less. The associated likelihood of leaving VU without graduating was much higher for the students with lower scores.

Consider the performance of the 90 students who left below track in first-semester calculus and the introductory meteorology course. Within first semester calculus, slightly more than half of these students earned a $\mathrm{C}+$ or lower, while a quarter did not complete the course. Within the introductory meteorology course, roughly half earned a $\mathrm{C}+$ or lower, but only 4 did not complete the course. Less than $20 \%$ of students who left below track earned a B- or better in each of these courses, yet changed majors after difficulty in subsequent coursework.

\section{Discussion}

While ACT scores are a predictive metric for undergraduate success in meteorology, there are other factors. Precollege preparation is critical for academic performance in the first year, which subsequently impacts student outcomes in the following years. Second-year enrollment is affected by first-year GPA and social engagement, while retention through year three is dependent on academic performance, precollege educational development, college commitment, and social connectedness. The role of social factors is consistent with prior models of student $\triangle$ Evaluation of student percentages within performance and graduation groups, given ranges of ACT Math scores. The percentages have been rounded to the nearest $0.1 \%$.

persistence in college, both of which assert that persistence is influenced by the match between the institution and student, as well as preparation for college. Ultimately, the fit of major and student interest affects the likelihood of success within a degree program; as an example within STEM, one study found that attitudes toward engineering influenced the likelihood of students staying within the major, while low SAT math scores increased the likelihood of being dismissed from engineering due to poor performance.

Testing critics have argued that test scores are primarily an indicator of socioeconomic status, with little additional value regarding the likelihood of student success. Assessing these claims quantitatively, a previous study found that while socioeconomic status is correlated with test scores, most of the sensitivity of academic performance to test metrics is independent of socioeconomic status. Another study affirmed the importance of test scores as predictors of college performance and found that socioeconomic status is a weak predictor of academic performance and retention.

\section{Conclusions}

Clearly, increased admission standards (at the program or university level) would increase retention within the meteorology program. 
There are ethical considerations, however, in modifying admissions standards. Students with a low ACT Math score have a strong chance of leaving the program after not doing well, but is it ethical to reject these students from trying, when some have completed the program and plenty of others graduated from the university with another major? The answers may not be clear, but perhaps a better balance can be achieved. Thankfully, better knowledge of academic risk can inform recruitment and advising of students. Academic difficulty typically appears within early coursework; most students with good performance in the first year are highly likely to succeed in the program. Those with difficulty can reassess approaches to learning, seek help, or change their course of study in a timely fashion.

It is fair to consider whether the results here are generalizable to other institutions. Although VU is not among the most selective universities, being a smaller private institution may nonetheless influence the student body (when compared with larger, public universities). However, it seems highly likely that the sensitivity to test scores is common to meteorology programs, since all such programs require rigorous mathematics. Large public universities typically report a wide range of incoming test scores, and sensitivity to test scores is present across a wide range of institutions and demographic factors.

This study does not include other student factors which may be important predictors, such as high school grade point average (GPA), class rank, and high school math courses. High school GPA is available for most of these students, but a scaling change associated with advanced coursework and the lack of math course information makes an evaluation difficult.

\section{$\equiv$ METADATA}

BAMS: What would you like readers to learn from this article?

Craig Clark: Meteorology is a challenging course of study, with a fairly high attrition rate. Higher test scores indicate greater chance of success, while those who struggle typically have trouble early in their degree program. A strong work ethic means a great deal, however, and many students are successful.

BAMS: How did you become interested in the topic of this article?

CC: Advising incoming students and meeting with high school visitors, it is clear that math preparation varies a great deal. The program has been interested in this for a long time, ultimately leading to this assessment.

BAMS: What surprised you the most in this study?

CC: I was surprised that ACT scores indicative of likely success start around 25, which is pretty good news. Higher scores indicate better chances, but you do not have to be off the charts to do well.

BAMS: What was the biggest challenge you encountered while doing this work?

CC: Making sure no students were missed! It gets tricky when a student registers for the semester in another major, changes to meteorology, then drops the major before the end of the semester. It took a little digging, but they are accounted for.

BAMS: What's next? How will you follow up?

CC: If data were available, an analysis of the highest high school math course completed would be really interesting. 


\section{AMS Publications introduces}

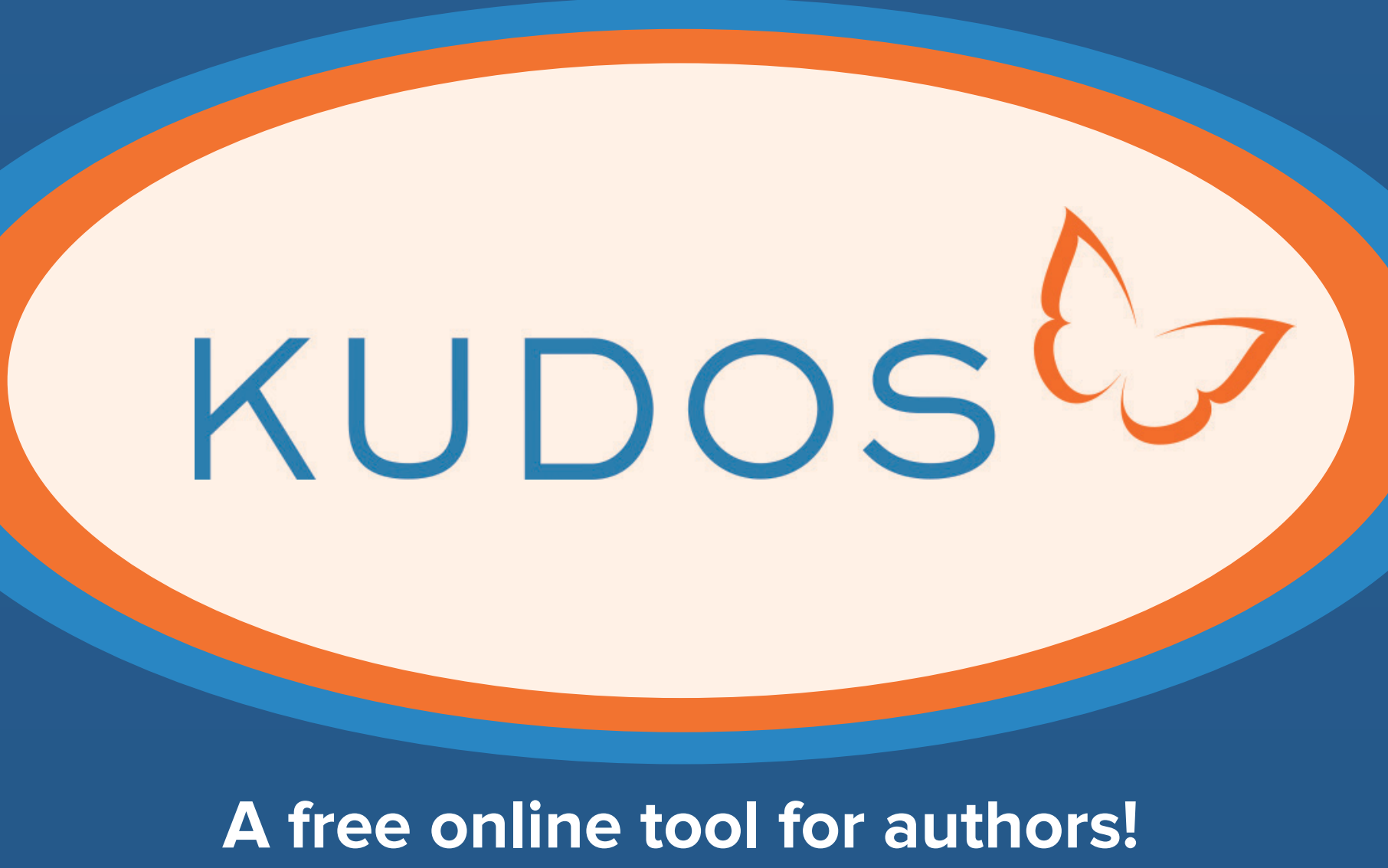

Communicate Your Research More Effectively

\section{Increase Your Work's Impact}

- Maximize citations and downloads of your article

- Open up your research to new audiences

- Explain and share your work in only 10 minutes

- Increase full-text article downloads by $23 \%$

- Access publication metrics via the author dashboard

Learn more about using Kudos with AMS

https://www.ametsoc.org/kudos/ 